\title{
Heterogeneity of gastric histology and function in food cobalamin malabsorption: absence of atrophic gastritis and achlorhydria in some patients with severe malabsorption
}

\author{
H Cohen, W M Weinstein, R Carmel
}

\begin{abstract}
Background-The common but incompletely understood entity of malabsorption of food bound cobalamin is generally presumed to arise from gastritis and/or achlorhydria.
\end{abstract}

Aim-To conduct a systematic comparative examination of gastric histology and function.

Subjects-Nineteen volunteers, either healthy or with low cobalamin levels, were prospectively studied without prior knowledge of their absorption or gastric status.

Methods-All subjects underwent prospective assessment of food cobalamin absorption by the egg yolk cobalamin absorption test, endoscopy, histological grading of biopsies from six gastric sites, measurement of gastric secretory function, assay for serum gastrin and antiparietal cell antibodies, and direct tests for Helicobacter pylori infection.

Results-The six subjects with severe malabsorption (group I) had worse histological scores overall and lower acid and pepsin secretion than the eight subjects with normal absorption (group III) or the five subjects with mild malabsorption (group II). However, histological findings, and acid and pepsin secretion overlapped considerably between individual subjects in group I and group III. Two distinct subgroups of three subjects each emerged within group I. One subgroup (IA) had severe gastric atrophy and achlorhydria. The other subgroup (IB) had little atrophy and only mild hypochlorhydria; the gastric findings were indistinguishable from those in many subjects with normal absorption. Absorption improved in the two subjects in subgroup IB and in one subject in group II who received antibiotics, along with evidence of clearing of $H$ pylori. None of the subjects in group IA responded to antibiotics.

Conclusions-Food cobalamin malabsorption arises in at least two different gastric settings, one of which involves neither gastric atrophy nor achlorhydria. Malabsorption can respond to antibiotics, but only in some patients. Food cobalamin malabsorption is not always synonymous with atrophic gastritis and achlorhydria, and hypochlorhydria does not always guarantee food cobalamin malabsorption. (Gut 2000;47:638-645)
Keywords: cobalamin; cobalamin malabsorption; atrophic gastritis; achlorhydria; pepsin; gastrin; Helicobacter pylori

Food cobalamin malabsorption, defined as the inability to absorb food bound or protein bound cobalamin while absorption of free cobalamin is intact, may be the most common form of cobalamin malabsorption. Evidence suggests that its frequency exceeds that of classical disorders of free cobalamin absorption such as pernicious anaemia. ${ }^{1}$ Nevertheless, the mechanisms responsible for food cobalamin malabsorption are incompletely understood.

Much clinical and laboratory evidence points to gastric dysfunction, especially loss of acid secretion, as a key factor. ${ }^{1-6}$ Although the stomach's role is undoubted, selection may have influenced the strength of that association ${ }^{7}$ because most of the initial studies identified gastric surgery, gastric atrophy, or use of acid suppressing drugs as predisposing conditions and selected their study subjects from such populations. ${ }^{2}{ }^{3}$ There has been no prospective systematic assessment of all the gastric correlates of food cobalamin malabsorption.

The present study was designed to address this gap in our understanding by examining gastric histology and gastric function in a blinded prospective fashion and comparing these characteristics with absorption results. The aim was to develop a profile of the stomach in food cobalamin malabsorption that could be compared concurrently with findings in subjects without malabsorption.

\section{Methods}

SUBJECTS

Most of the subjects were recruited during a community survey of cobalamin status in apparently healthy elderly subjects. ${ }^{8}$ Proportionately more subjects found to have low rather than normal cobalamin levels during the survey volunteered for the study, but their absorption status was not known beforehand. All participants were community dwellers and had no contraindications for the test procedures. Subjects with a history of gastrointestinal surgery (other than remote appendicectomy or cholecystectomy) or receiving acid suppressive medications were excluded. Although our initial

Abbreviations used in this paper: EYCAT, egg yolk cobalamin absorption test; MAO, maximum acid output. 
focus was on volunteers $>60$ years old, six subjects below that age were subsequently accepted. The only subjects that were not recruited from a presumably healthy population were two patients who had been referred for testing because of mild cobalamin deficiency. The objective of the recruitment was to provide enough subjects with and without malabsorption for comparative analyses of gastric status, rather than to determine the prevalence rates of malabsorption. Median age of the subjects was 69 years (range 33-81), 11 were men and eight were women, and there were 12 whites, four blacks, two Latin Americans, and one AsianAmerican. The study was approved by the institutional review board at the Los Angeles County-USC Medical Center and each participant gave written informed consent.

\section{ABSORPTION TESTING}

The egg yolk cobalamin absorption test (EYCAT) method, modified from that of Doscherholmen and colleagues ${ }^{9}$ by omitting the dual isotope feature, has been previously described. ${ }^{10}$ In brief, ${ }^{57} \mathrm{Co}-$ cyanocobalamin and unlabelled cobalamin were mixed with reconstituted lyophilised egg yolk in a Waring blender. The egg yolk preparation was scrambled in a Teflon coated skillet, and 12 or $13,50 \mathrm{~g}$ portions were weighed out from this batch and stored at $-20^{\circ} \mathrm{C}$ until use. Each portion contained about $0.8 \mu \mathrm{g}$ of cobalamin (approximately $0.5 \mu \mathrm{Ci}$ of ${ }^{57} \mathrm{Co}$ ). On the day of testing, the fasted subject ate the scrambled egg yolk portion that had been reheated in a microwave oven; no other food or liquids were taken for four hours. The rest of the procedure was the same as in the standard Schilling test, with an intramuscular injection of $1000 \mu \mathrm{g}$ of cyanocobalamin given two hours after the test meal. A 24 hour urine collection was done. The radioactivity excreted was compared with a $1 \mathrm{~g}$ egg yolk cobalamin standard from the original batch preparation.

Based on results in 168 normal and abnormal subjects, 24 hour excretion values below $1 \%$ indicate severe food cobalamin malabsorption and values $\geqslant 2 \%$ represent normal absorption. Values of $1.00-1.99 \%$ represent probable or mild malabsorption. EYCAT reproducibility had been shown in the retesting of seven subjects within 1-6 months. Two subjects with severe malabsorption had repeat values of $0.43 \% / 0.24 \%$ and $0.19 \% / 0.17 \% / 0.10 \%$, respectively. Five subjects with normal absorption had repeat values of $4.06 \% / 4.10 \%$, $4.66 \% / 5.38 \%, 2.67 \% / 3.63 \%, 2.85 \% / 3.21 \%$, and $2.91 \% / 2.25 \%$, respectively.

After baseline blood samples were obtained, all fasted volunteers underwent the EYCAT. In order to rule out pernicious anaemia (defined gastroenterologically here as malabsorption of free cobalamin due to loss of intrinsic factor secretion) as the explanation for any abnormal EYCAT results, standard Schilling tests, which measure absorption of free cobalamin, were performed in all subjects with abnormal EYCAT results who agreed to undergo the test. Patients with pernicious anaemia absorb both free and food bound cobalamin poorly and usually have EYCAT results below $1 \% .^{2}{ }^{10}$
Because a normal EYCAT result is presumptive proof that absorption of free cobalamin is also normal, Schilling tests were rarely done in patients with normal food cobalamin absorption. Other markers of pernicious anaemia, such as gastric intrinsic factor secretion, gastrin levels, and antibodies to intrinsic factor, were also assessed in most patients. As a result, two subjects with findings suspicious of pernicious anaemia were excluded from the study and are not presented here.

\section{ENDOSCOPY AND BIOPSY}

After absorption testing, each volunteer underwent upper gastrointestinal endoscopic examination. The procedure was performed by an investigator who was blinded to the subject's absorption test results. Biopsies were taken from standardised sites as shown in fig 1, using a large capacity pinch biopsy forceps with an $8 \mathrm{~mm}$ open span. The two biopsies on the greater curve of the body (mid body and $3 \mathrm{~cm}$ distal to it) were designed to sample the oxyntic mucosa where the folds are thickest. The biopsy of the mid body lesser curve was designed to help complete the overall picture of the status of the oxyntic mucosa, fully recognising that oxyntic glands in the lesser curve of the body are often thinner and gastritis, if present, may appear to be more severe. ${ }^{11}$

All biopsies were mounted mucosal side up on a plastic mesh and fixed in Bouin's solution for 2-6 hours before transfer to $70 \%$ alcohol and subsequent processing for paraffin embedding. Two slides each containing 15 serial sections at $4 \mu \mathrm{m}$ were prepared, one for haematoxylin and eosin staining and the second for staining with haematoxylin and eosin-alcian blue, $\mathrm{pH} 2.5$, to facilitate detection and grading of intestinal metaplasia. Four to five additional sections were stained with the Genta stain for identification of $\mathrm{H}$ pylori. ${ }^{12}$

\section{HISTOLOGICAL ASSESSMENT}

Biopsy specimens were coded, mixed, and evaluated by a single observer without knowledge of any of the other findings. A similarly blinded observer examined the specially stained tissue sections for $H$ pylori.

\section{Gastritis index}

Gastric inflammatory, epithelial, and glandular changes were scored separately in a similar fashion to that described previously. ${ }^{13}$ For inflammation, neutrophils and mononuclear cells were each graded separately with scores of

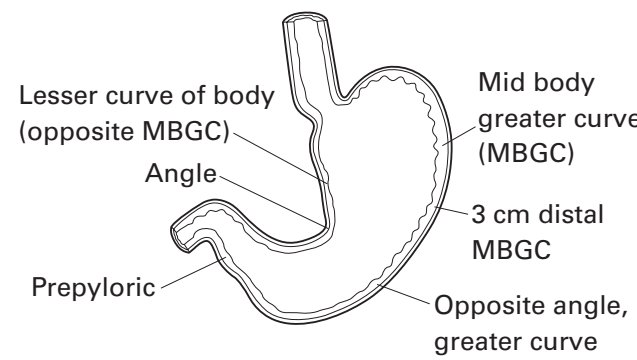

Figure 1 Diagrammatic representation of the gastric biopsy sites. 
$0-3$, yielding a combined inflammatory cell density score ranging from 0 to 6 . A score of 1 for neutrophils represented 1-2 extravascular foci of neutrophils in the lamina propria or the epithelium. A grade of 2 represented 3-4 such foci, and a grade of 3, >4 foci. Grade 3 generally reflected the presence of neutrophil collections in every high power field. For mononuclear cells, a grade of 1 represented a perceived mild increase, whereas grade 3 represented dense infiltrates creating an apparent increased space between adjacent pits (foveolae) with or without extension into the subjacent glands. The surface and pit epithelia were assessed separately on scales of $0-3$, with an overall epithelium score of $0-6$. The grades of mild to severe changes (scores 1-3) integrated the severity and diffuseness of epithelial abnormalities on serial sections. The abnormalities that were especially noted were mucin depletion with cytoplasmic basophilia, disturbed nuclear polarity, enlarged nuclei, and prominent nucleoli. Different gastric components were assessed separately. The scores for inflammation and epithelium were summed up in a "gastritis index score" of 0-12.

\section{Atrophy score}

The presence or absence of atrophy in the oxyntic mucosa, especially from the greater curve, was a central question in this study. The oxyntic mucosa consists of very shallow pits and most of the thickness of the mucosa is occupied by glands (fig 2). An atrophy grade was given to help provide a simple "mind's eye" view of the appearance of the gastric mucosa in terms of the presence or absence of atrophy. A score of 0 represented no atrophy, a score of 1 represented non-atrophic inflammation (superficial gastritis), and scores of 2, 3, and 4 represented increasing degrees of atrophy based on a perception of loss of glands involving the top, middle, and bottom thirds of the mucosal gland zone, respectively. This loss could be associated with either inflammatory cells encroaching into, and seemingly replacing, glands

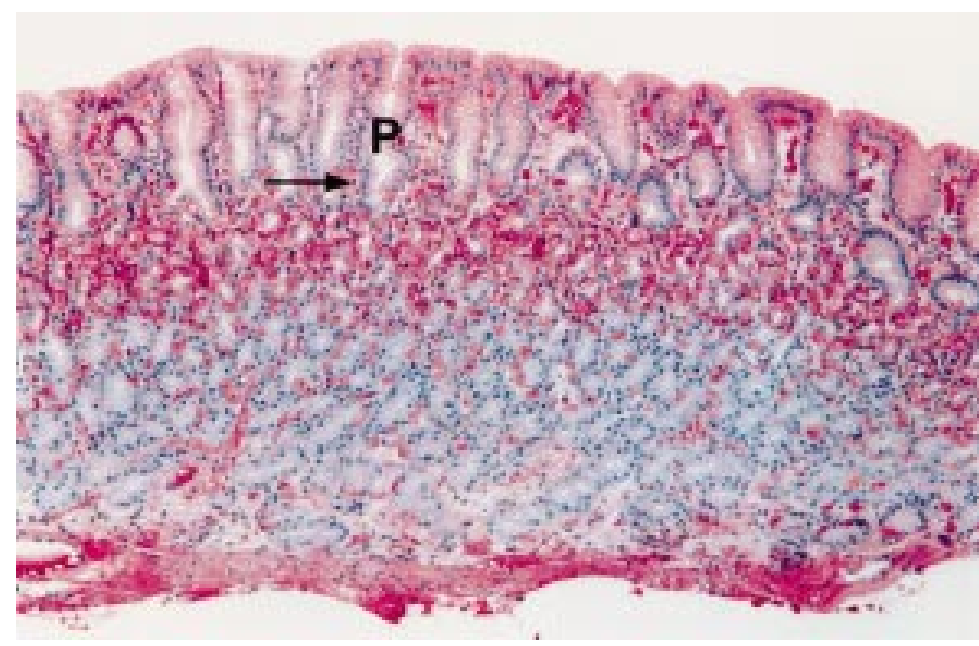

Figure 2 Low power view of a normal appearing oxyntic biopsy from the mid body greater curvature from subject No 14 in group III. Note that the pits $(P)$ are close together (arrow), not separated as in figure 4 by inflammatory cells. The band of predominantly red staining cells below the pits is where parietal cells are concentrated. The predominantly blue staining gland zone beneath that band is where chief cells are concentrated. or with intestinal metaplasia or both. Restated, grade 2 represents mild loss of glands and grade 4 marked loss of glands.

Intestinal metaplasia was graded $0-4$ based on the estimate of the horizontal span involvement by quartiles. Grade 1 represents up to $25 \%$ intestinalisation of the horizontal span of the epithelium and grade 4 represents $>75 \%$ involvement. As mentioned previously, the presence of full thickness mucosal intestinal metaplasia mandated a score of severe atrophy (grade 4) for either oxyntic or antral mucosa.

Antral glands occupy less than $50 \%$ of the overall thickness of the mucosa. Therefore, atrophy was graded as present (score 4) or absent. Because the foveolae and intervening lamina propria occupy most of the antral mucosal plane of thickness, scores for superficial non-atrophic gastritis were graded as 1 (mild), 2 (moderate), and 3 (severe).

\section{GASTRIC SECRETORY STUDIES}

Several days after endoscopy, gastric intubation was performed in the fasted subject without radiographic monitoring. Basal and pentagastrin stimulated $(6 \mu \mathrm{g} / \mathrm{kg})$ gastric aspirates were each collected for one hour by continuous suction. Volume and $\mathrm{pH}$ by glass electrode were measured, and maximum acid output (MAO) was calculated in $\mathrm{mEq} / \mathrm{h}$. Pentagastrin stimulated gastric juice was also neutralised and assayed for intrinsic factor content ${ }^{14}$ and pepsin concentration. ${ }^{15}$

\section{HELICOBACTER PYLORI TESTING}

In addition to the "gold standard" of histological assessment of $H$ pylori, as described above, subjects were tested by ${ }^{13} \mathrm{C}$ urea breath testing (Meretek Diagnostics, Nashville, Tennessee, USA).

\section{BACTERIAL CULTURES}

Gastric aspirates for quantitative cultures were collected into a sterile container at the time of endoscopy via the biopsy channel of the endoscope before air insufflation, after discarding the initial aspirate of about $3 \mathrm{ml}$. An attempt was also made to obtain fluid from the duodenal lumen via a catheter inserted through the biopsy channel of the endoscope at the time of endoscopy. Cultures were considered positive when $>10^{5}$ organisms $/ \mathrm{ml}$ were obtained. Because our sampling technique did not guarantee exclusion of air, anaerobic culture results are not included.

\section{STATISTICAL ANALYSIS}

Data were tabulated and analysed by standard statistical methods using SAS for Windows software version 6.08 (SAS Institute, Cary, North Carolina, USA). These included Student's $t$ test, Wilcoxon test, logistic regression analysis, Fisher's exact test, and Spearman's and Pearson's correlations as appropriate.

\section{Results}

Eleven of 19 subjects had food cobalamin malabsorption, although this should not be construed as a prevalence rate. Malabsorption was severe in six (group I; EYCAT $<1.00 \%$ ) and 
Table 1 Characteristics of the study subjects and results of absorption tests and tests of gastric function

\begin{tabular}{|c|c|c|c|c|c|c|c|c|}
\hline \multirow[b]{2}{*}{ Subject No } & \multirow[b]{2}{*}{$\begin{array}{l}\text { Age, race, } \\
\text { sex }\end{array}$} & \multirow[b]{2}{*}{$\begin{array}{l}E Y C A T \\
(\% / 24 h)\end{array}$} & \multirow[b]{2}{*}{$\begin{array}{l}\text { Schilling test } \\
(\% / 24 h)\end{array}$} & \multirow[b]{2}{*}{$\begin{array}{l}\text { Serum cobalamin } \\
(p m o l / l)\end{array}$} & \multirow[b]{2}{*}{$\begin{array}{l}\text { Serum gastrin } \\
(n g / l)\end{array}$} & \multicolumn{3}{|l|}{ Gastric } \\
\hline & & & & & & $\begin{array}{l}M A O \\
(m E q / h)\end{array}$ & $\begin{array}{l}\text { Pepsin } \\
(U / m l)\end{array}$ & $\begin{array}{l}\text { IF } \\
(\text { nmol/l) }\end{array}$ \\
\hline \multicolumn{9}{|c|}{ Group I-severe food cobalamin malabsorption } \\
\hline 1 & $33 / \mathrm{L} / \mathrm{F}$ & 0.19 & 12.2 & 一 $^{\star}$ & 1269 & 0 & 135 & 13.9 \\
\hline 2 & $74 / \mathrm{L} / \mathrm{M}$ & 0.43 & 17.6 & 223 & 87 & 0 & 80 & 12.0 \\
\hline 3 & $77 / \mathrm{W} / \mathrm{M}$ & 0.67 & 11.2 & $171+$ & 1155 & 0 & 61 & 0.8 \\
\hline 4 & $58 / \mathrm{W} / \mathrm{F}$ & 0.01 & 9.9 & $129^{\circ}$ & 91 & 5.28 & 551 & 27.4 \\
\hline 5 & 70/W/M & 0.41 & 15.2 & 109 & 217 & 4.02 & 563 & 37.3 \\
\hline 6 & $57 / \mathrm{B} / \mathrm{F}$ & 0.22 & - & 241 & 82 & - & - & $11.7 \S$ \\
\hline \multicolumn{9}{|c|}{ Group II-mild food cobalamin malabsorption } \\
\hline 7 & $66 / \mathrm{W} / \mathrm{F}$ & 1.00 & - & 443 & 80 & - & - & - \\
\hline 8 & $73 / \mathrm{W} / \mathrm{F}$ & 1.16 & - & 235 & 54 & - & - & - \\
\hline 9 & $67 / \mathrm{B} / \mathrm{F}$ & 1.21 & - & $466 \dagger$ & 75 & 2.80 & 649 & 51.2 \\
\hline 10 & 79/W/M & $1.34 / 1.69$ & - & $117^{\circ}$ & 101 & 14.71 & 373 & 74.8 \\
\hline 11 & 71/W/M & 1.88 & 20.0 & 51 & 92 & - & - & - \\
\hline \multicolumn{9}{|c|}{ Group III-normal absorption } \\
\hline 12 & $44 / \mathrm{B} / \mathrm{F}$ & 2.62 & - & 347 & 67 & 8.64 & 557 & 25.0 \\
\hline 13 & $56 / \mathrm{W} / \mathrm{M}$ & 2.85 & - & 387 & 169 & 2.25 & 43 & 63.8 \\
\hline 14 & $68 / \mathrm{A} / \mathrm{M}$ & 3.53 & - & 292 & 45 & 11.44 & 912 & 18.0 \\
\hline 15 & $81 / \mathrm{B} / \mathrm{M}$ & 3.87 & 19.5 & 278 & 90 & 7.70 & 869 & 41.9 \\
\hline 16 & $72 / \mathrm{W} / \mathrm{M}$ & 4.08 & - & 141 & 55 & 13.91 & 612 & 44.5 \\
\hline 17 & $69 / \mathrm{W} / \mathrm{F}$ & 4.38 & - & 273 & 54 & 2.76 & 551 & 81.6 \\
\hline 18 & 48/W/M & 5.53 & - & 212 & 119 & 2.56 & 551 & 33.1 \\
\hline 19 & 70/W/M & 8.92 & 26.5 & 134 & 40 & 40.31 & 575 & 52.0 \\
\hline Normal & & $>2$ & $>8$ & $>140$ & $<125$ & $>5.0$ & $>220$ & $>1.3$ \\
\hline
\end{tabular}

EYCAT, egg yolk cobalamin absorption test; MAO, maximal acid output; IF, intrinsic factor; W, white; B, black; L, Latin American; A, Asian; F, female; $M$, male.

$\star$ This subject was referred for study after being treated for low cobalamin level.

†Although this subject had a normal cobalamin level, methylmalonic acid and/or homocysteine levels were abnormal.

$\S$ This normal IF concentration was obtained from a basal gastric juice (the subject refused gastric stimulation with pentagastrin).

mild in five (group II; EYCAT 1.00-1.99\%).

The remaining eight subjects had normal absorption (group III; EYCAT $\geqslant 2.00 \%$ ). The findings in the three groups are shown in table 1.

Schilling test results were normal in all eight subjects tested, including the five subjects with severe malabsorption. None of the 19 subjects in any of the groups had anti-intrinsic factor antibodies. Further proof that pernicious anaemia (free cobalamin malabsorption due to lack of intrinsic factor) was not present in any of the 19 subjects was provided by normal intrinsic factor levels in 15 of 16 subjects who underwent gastric testing; the remaining subject (No 3) had subnormal, but not absent, intrinsic factor. He was not regarded as having pernicious anaemia because his normal Schilling test result showed that he did not malabsorb free cobalamin; indeed, the Schilling test result was again normal when he was retested six months later. Only two of the 19 volunteers had antiparietal cell antibodies, both of whom were in group I and had severe gastritis and achlorhydria (subject Nos 1 and

Table 2 Results of gastric histology

\begin{tabular}{|c|c|c|c|c|c|c|c|}
\hline \multirow[b]{2}{*}{ Subject No } & \multicolumn{2}{|c|}{ Corpus histology } & \multicolumn{2}{|c|}{ Antrum histology* } & \multicolumn{3}{|c|}{ Gastritis index score* } \\
\hline & $\begin{array}{l}\text { Atrophy } \\
\text { (greater } \\
\text { curve) } t\end{array}$ & $\begin{array}{l}\text { Intestinal } \\
\text { metaplasia }\end{array}$ & AtrophyS & $\begin{array}{l}\text { Intestinal } \\
\text { metaplasia }\end{array}$ & Corpus & Antrum & $\begin{array}{l}\text { H pylori } \\
\text { stain }\end{array}$ \\
\hline \multicolumn{8}{|c|}{ Group I-subgroup IA } \\
\hline 1 & 4.0 & 1.0 & 0 & 0 & 2.3 & 0 & Negative \\
\hline 2 & 4.0 & 4.0 & 3.3 & 2.7 & $3.0 \pi$ & 1.3 & Negative \\
\hline 3 & $4.0 \pi$ & $3.5 \%$ & 0 & 0 & 1.5 & 1.3 & Negative \\
\hline \multicolumn{8}{|c|}{ Group I-subgroup IB } \\
\hline 4 & 1.0 & 0 & 1.0 & 0 & 1.3 & 3.0 & Positive \\
\hline 5 & 2.0 & 0.3 & 3.3 & 1.0 & 9.3 & 9.3 & Positive \\
\hline 6 & 2.0 & 0 & 3.3 & 2.0 & 5.3 & $4.5 \pi$ & Positive \\
\hline \multicolumn{8}{|l|}{ Group II } \\
\hline 7 & 1.0 & 0 & 1.0 & 0 & 2.0 & 3.3 & Positive \\
\hline 8 & 0 & 0 & 0.3 & 0 & 0 & 0.3 & Negative \\
\hline 9 & 2.5 & 0.3 & 2.3 & 0 & 7.0 & 5.3 & Positive \\
\hline 10 & 2.5 & 0 & 3.7 & 0.3 & 6.0 & 6.7 & Positive \\
\hline 11 & 0 & 0.7 & 0 & 0 & 0.3 & 0 & Negative \\
\hline \multicolumn{8}{|l|}{ Group III } \\
\hline 12 & 0.5 & 0 & 0 & 0 & 0.3 & 0 ๑ & Negative \\
\hline 13 & 1.5 & 0 & 1.7 & 0 & 3.3 & 3.3 & Positive \\
\hline 14 & 0 & 0 & 0.3 & 0 & 0.7 & 0.7 & Negative \\
\hline 15 & 1.0 & 0 & 2.7 & 0.3 & 2.3 & 6.7 & Positive \\
\hline 16 & 1.0 & 0 & 4.0 & 1.0 & 5.3 & 8.7 & Positive \\
\hline 17 & 0.5 & 0 & 1.0 & 0.3 & 0.3 & 2.3 & Negative \\
\hline 18 & 2.0 & 0.3 & 2.7 & 0.7 & 5.3 & 7.3 & Positive \\
\hline 19 & 0 & 0 & 0 & 0 & 0 & 0 & Negative \\
\hline
\end{tabular}

${ }^{\star}$ Mean score of three sites.

†Mean of two sites along the greater curve.

\Only grade 4 indicates atrophy; grades $1-3$ represent mild, moderate, or severe grades of superficial gastritis. The score represents the maximum severity of involvement in any portion of the antrum, and thus a worst case scenario. The intestinal metaplasia score, in turn, reflects the horizontal extent of the biopsy occupied by the metaplasia (see methods section).

qData missing from one site. 


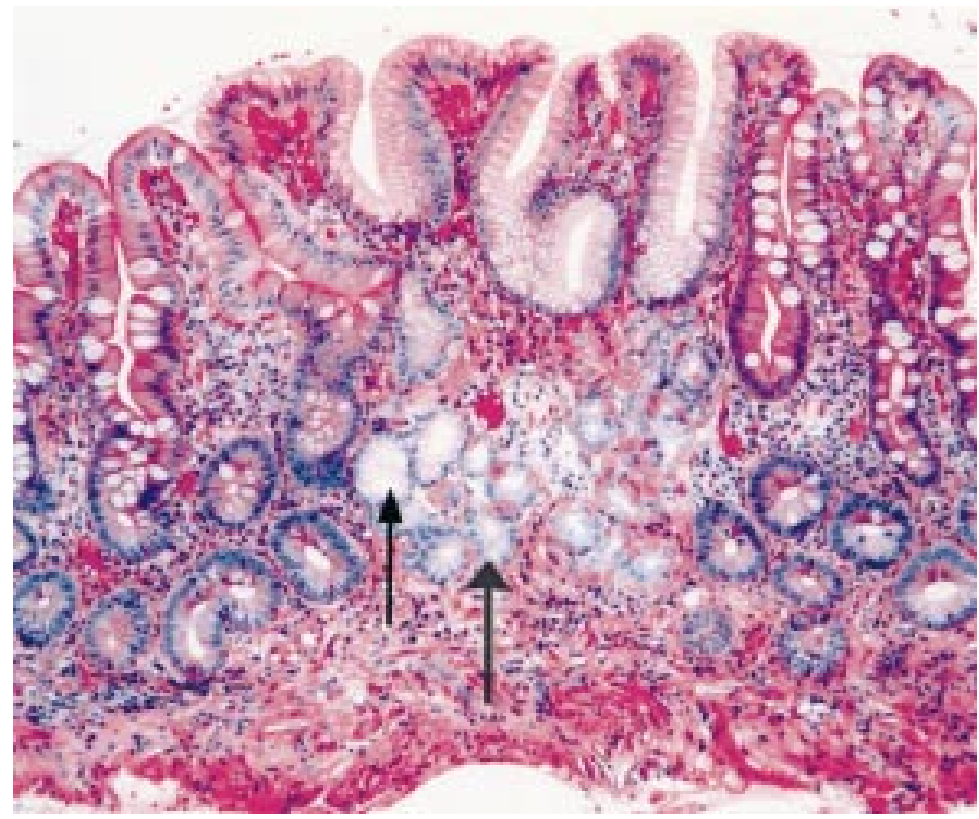

Figure 3 Severe atrophic gastritis of the mid body greater curvature in subject No 2 in subgroup IA with severe food cobalamin malabsorption. Most of the section shows full thickness intestinal metaplasia with villi lined by enterocytes and goblet cells. The centre is lined by gastric surface epithelium and, beneath it, a small group of residual glands. The clear staining glands (thin arrow) are metaplastic mucous glands (pseudopyloric

metaplasia). The blue and red cells in the centre are chief and parietal cells (thick arrow).

3); their normal Schilling test results ruled out a diagnosis of pernicious anaemia.

HISTOLOGICAL FINDINGS AND HELICOBACTER PYLORI STATUS (TABLE 2)

Atrophy grade (reflecting the severity of atrophy) for oxyntic biopsy sites E and F was significantly higher in group I than in group III $(\mathrm{p}=0.003)$. Mean (SD) overall grades were 2.8 (1.2) in group I compared with $1.2(1.0)$ in group II and $0.8(0.7)$ in group III $(\mathrm{p}=0.01)$.

However, the most striking aspect of the histological findings was that they differed among the six group I subjects despite the subjects' equally severe malabsorption (table 2 ). Subject Nos 1-3 were therefore designated subgroup IA because they had severe oxyntic gland atrophy and intestinal metaplasia (exemplified in fig 3). They also had achlorhydria (see below). In contrast, subject Nos 4-6 were assigned to subgroup IB because they did not have atrophy (exemplified in fig 4). They were $H$ pylori positive and their major histological scores, that is the gastritis index score and degree of corpus atrophy and intestinal metaplasia, were not significantly different from those of $H$ pylori infected subjects without malabsorption (group III) or with only mild malabsorption (group II; exemplified in fig 5).

Ten subjects nearly equally distributed among the three absorption groups were $H$ pylori positive by histological stain (table 2) as well as ${ }^{13} \mathrm{C}$ urea breath testing; the remainder were negative on both tests. Unlike the overlap in gastritis index scores between groups I and III (3.48 (3.16) $v 2.91$ (2.79); $\mathrm{p}=0.72)$, the scores were significantly different between $H$ pylori infected and uninfected subjects (5.28 (2.20) $v 0.79$ (0.71); $\mathrm{p}=0.0003$ for all six sites combined).

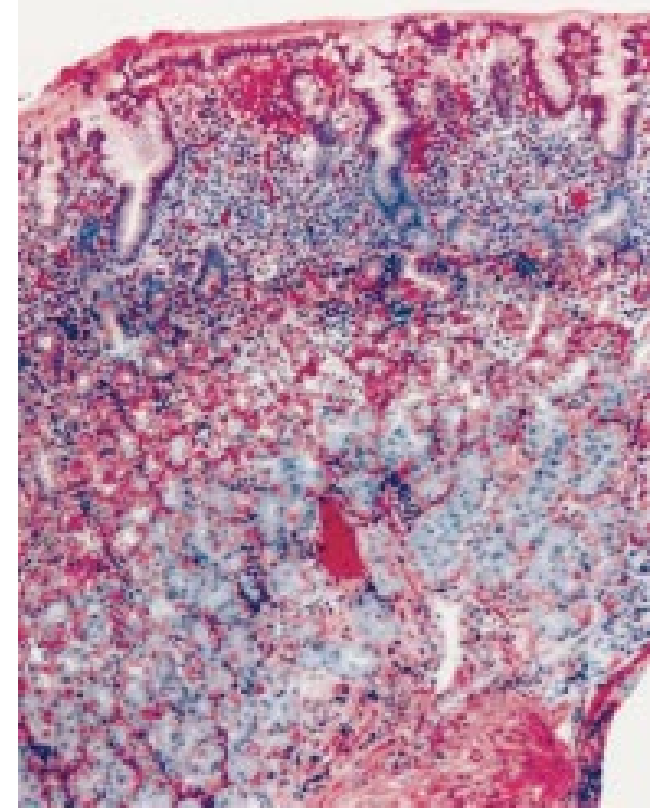

Figure 4 Mid body biopsy from subject No 6 in subgroup IB. A dense infiltrate separates the gastric pits (contrast with fig 2). There is encroachment of inflammatory cells beneath the pits into the uppermost part of the gland zone. This was graded as mild atrophic gastritis. It could be argued, however, that this is the severe end of the superficial gastritis spectrum, which would only strengthen the concept that severe malabsorption occurs in the absence of atrophy.

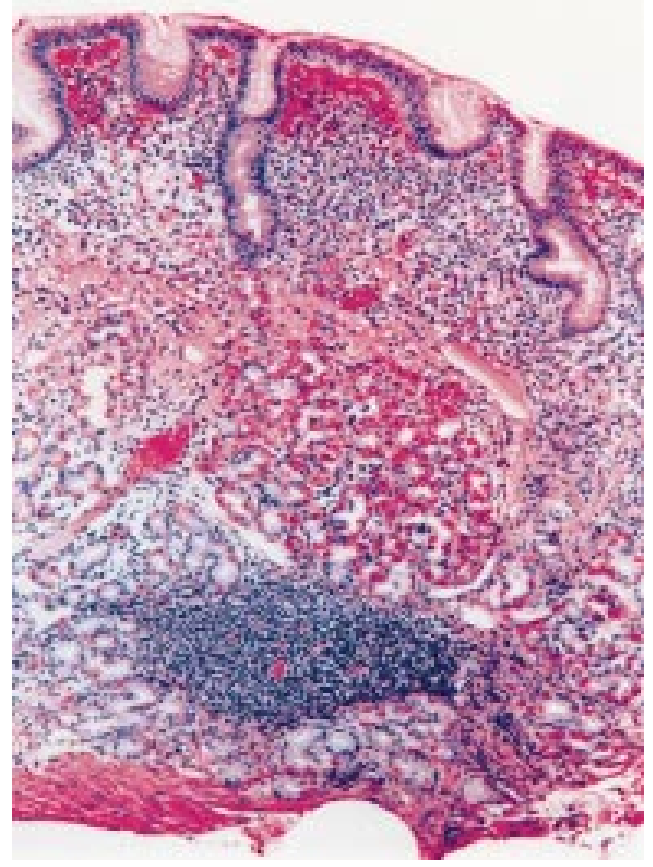

Figure 5 Biopsy from the mid body in subject No 10 from group II with mild food cobalamin malabsorption.

Inflammatory cells separate the pits, similar to fig 4. A plug of oxyntic glands sits atop a lymphoid aggregate. To the left is pink staining oedema fluid.

As reflected by the gastritis index scores in table 2, the severity of inflammation in the antrum was similar to that of the body $(r=0.8$, $\mathrm{p}<0.0001)$. However, only subject No 16 in group III, who had normal acid secretion, had antral atrophy (grade 4.0). Intestinal metaplasia was minimal, which suggests that the antral 
atrophy in subject No 16 (and the severe superficial gastritis in subjects Nos 5, 6, and 10) was focal rather than extensive.

GASTRIC SECRETION RESULTS (TABLE 1)

Pentagastrin stimulated gastric juice was examined in 15 of 22 subjects; the 16 th subject (No 6) only allowed collection of her basal specimen which thus provided limited information. MAO, which did not correlate with age, sex, $H$ pylori status, or gastric index scores, correlated inversely with corpus atrophy scores $(\mathrm{p}=0.001)$ and was lower in group I than in group III (1.86 (2.59) v $11.20(12.53) \mathrm{mEq} / \mathrm{h} ; \mathrm{p}=0.047)$. Gastric pepsin concentrations, which also correlated inversely with corpus atrophy scores $(p=0.02)$, were also lower in group I although the difference between groups I and III did not achieve statistical significance (278 (115) v 584 (93) $\mathrm{U} / \mathrm{ml} ; \mathrm{p}=0.064$ ).

Despite the significant overall differences, some overlap in MAO values was seen between groups I and III. Several subjects with normal absorption had lower MAO than two of the severely malabsorbing subjects (subject Nos 4 and 5). An overlap in gastric pepsin concentration was also noted. Indeed, subject No 13, whose absorption was normal, had the lowest pepsin concentration in the entire study.

The most striking gastric secretory finding was that subjects in group I could be divided into the same two distinct subgroups (IA and IB) as their histological and $H$ pylori findings (table 2). All three subjects in subgroup IA had achlorhydria and low pepsin concentrations, as expected in gastric atrophy (table 1). Two of the three also had very high serum gastrin levels and positive antiparietal cell antibodies; the third (subject No 2) had normal gastrin levels presumably because he alone also had diffuse antral intestinal metaplasia and atrophy. In contrast, both subjects in subgroup IB whose stimulated gastric juice was available had normal pepsin secretion and only mild hypochlorhydria despite equally severe malabsorption; they also had either normal or only minimally elevated serum gastrin levels and did not have antiparietal cell antibodies (table 1). As mentioned previously, their histological findings were not unlike those in group III (table 2).

No bacterial growth was found in 12 of the 15 gastric juices and in five of the eight duodenal aspirates that were cultured. In total, five subjects, all with malabsorption, had positive cultures for either or both fluids (subjects Nos 1, 2, 3, 5, and 10). Alpha and gamma Streptococci, Neisseria, Xanthomonas, and/or Pseudomonas species were identified among the different subjects.

RESPONSE TO ANTIBIOTICS

Five subjects with severe malabsorption (subject Nos 1-5) and one with mild malabsorption (subject No 10) were treated with oral antibiotics. These six subjects included all five who had positive aerobic bacterial cultures and three who were positive for $H$ pylori. Tetracycline was given alone for one week or, in subject
No 5, for two weeks together with metronidazole and bismuth subsalicylate.

On retesting 1-7 days after completion of antibiotics, the abnormal EYCAT results did not improve in the three subjects in subgroup IA, who were all achlorhydric and had severe gastric atrophy. All three non-responders were also $H$ pylori negative but had positive gastric and duodenal aerobic bacterial cultures. In contrast, EYCAT improved in subjects Nos 4 (from $0.01 \%$ to $2.07 \%$ ), 5 (from $0.41 \%$ to $1.45 \%$ and $1.26 \%$ ), and 10 (from $1.34 \%$ and $1.69 \%$ to $5.40 \%$ ); all three responders had much less severe histological changes than non-responders and had normal or borderline $\mathrm{MAO}, H$ pylori infection, and variable aerobic bacterial growth. All three subjects who improved also "cleared" their $H$ pylori infection by histological and breath test criteria within one week of treatment. Interestingly, $H$ pylori infection recurred in subject No 10 as his EYCAT returned towards his pretreatment values $(1.87 \%$ and $2.22 \%)$. The responders and non-responders could not be distinguished by their pretreatment aerobic bacterial cultures, which had been positive in nearly all cases. None of the gastric biopsies repeated after antibiotic treatment showed significant changes compared with their histological findings before treatment, apart from disappearance of $H$ pylori.

\section{Discussion}

Food cobalamin malabsorption occurs when the vitamin cannot be released from its binding to proteins in food and fails to become available for intrinsic factor mediated absorption. ${ }^{1}$ The release process has been shown by in vivo and in vitro studies to require acid and pepsin and is presumed to occur in the stomach. ${ }^{1-6}$ Therefore, gastric dysfunction is viewed as the key to any malfunction. Indeed, food cobalamin malabsorption was first described in patients with gastric resection, vagotomy, or gastritis with achlorhydria. ${ }^{23}$ Subsequent studies showed that acid suppressive drugs often depressed food cobalamin absorption also. ${ }^{6} 1617$

Nevertheless, this may be only a partial picture of the process and its disorders. The frequent selectivity for patients with gastric dysfunction in clinical studies of food cobalamin malabsorption, including most of the pioneering studies, may have contributed to an exclusive emphasis on achlorhydria. However, recurrent indications that achlorhydria alone may not explain all cases of malabsorption $^{5}{ }^{10}$ 18-20 $^{10}$ and the lack of systematic information on gastric status suggested that a prospective comparison of gastric histology and function was needed in subjects with and without food cobalamin malabsorption who were not selected for known gastric dysfunction a priori.

The present results show that even though subjects with severe malabsorption (group I) had, overall, significantly lower acid secretion and worse histological findings in the corpus than those with normal absorption (group III), there were important and frequent exceptions. 
There was an overlap in both gastric function and histology between individual members of the three groups. The overlap in gastric function was evident to the extent that three of eight subjects with normal absorption and one of two subjects with mild malabsorption had poorer acid secretion than several subjects with severe malabsorption (table 1 ). This variability shows that hypochlorhydria and low pepsin levels occur both with and without malabsorption and therefore are not always sufficient in themselves to induce food cobalamin malabsorption.

The most noteworthy finding was the identification of two distinct subsets of gastric characteristics within group I, the group with severe malabsorption. Subgroup IA had the severe gastric atrophy, achlorhydria, and diminished pepsin secretion that fit the dominant model of food cobalamin malabsorption in the literature. Two of these three individuals also had marked hypergastrinaemia and positive antiparietal cell antibodies.

In contrast, subgroup IB presented a different picture. Hypochlorhydria was mild, pepsin secretion was adequate, and gastric histology, especially in the greater curve, showed notably mild abnormalities. In these characteristics, the functional and histological status of the stomach in subgroup IB was virtually indistinguishable from that found in many of the subjects whose absorption was normal (group III). It was largely these subjects who were responsible for the overlaps mentioned previously.

The existence of subgroups IA and IB, even though the numbers of subjects were small, is important because it clearly indicates that atrophic gastritis and achlorhydria are not the sole settings in which severe food cobalamin malabsorption occurs. However, despite the suggestiveness of active, biopsy proven $H$ pylori infection in all three subjects in subgroup IB but in none of the subjects in subgroup IA, the nature of the alternative mechanism or mechanisms remains unclear.

Suter and colleagues ${ }^{18}$ reported that antibiotics improved food cobalamin malabsorption. They proposed that upper gastrointestinal anaerobes play a role in the malabsorption, although their in vitro studies showed no direct effect of anaerobes. $H$ pylori status was not studied. Close examination of response to antibiotics was not a primary intent of our study, but we confirmed that antibiotics can reverse food cobalamin malabsorption. Unlike Suter and colleagues, ${ }^{18}$ however, we found that such a response is not universal but occurs in only some patients. The presence of achlorhydria and severe atrophy (subgroup IA) appeared to preclude any response to antibiotics, whereas subjects with mild gastric changes and active $H$ pylori infection improved (subgroup IB or group II). The presence of aerobic bacterial contamination did not seem to distinguish between responders and non-responders. However, anaerobic cultures were not obtained.

Antibody findings and urea breath test data have indicated a significant epidemiological association between $H$ pylori infection and severe food cobalamin malabsorption. ${ }^{19}{ }^{21}$ Based on those results and our present observations, and despite the fact that many infected subjects both here and in previous studies did not have malabsorption, the possibility that the response to antibiotics was due to suppression of $H$ pylori must be considered. Gastritis induced by $H$ pylori is known to reverse with antibiotics, with increased acid secretion within one week. ${ }^{22}$ Nevertheless, differentiation between suppression of $H$ pylori or bacteria as the operative antibiotic effect is not possible from our data. While suggestive, the findings permit no definitive conclusion about the role of $H$ pylori in food cobalamin malabsorption. Neither $H$ pylori nor bacterial infection was specific to food cobalamin malabsorption in our subjects.

In summary, our data clearly demonstrate that severe food cobalamin malabsorption can occur in patients who do not have atrophic gastritis of the oxyntic mucosa or achlorhydria. One immediate practical conclusion is that food cobalamin malabsorption should never be automatically equated with atrophic gastritis, contrary to some proposals. ${ }^{20}$ Indeed, those investigators stretched the concept by ignoring absorption test results if they conflicted with gastric histology findings. ${ }^{20}$ Nor should serum markers of atrophic gastritis be substituted for direct tests of food cobalamin absorption, which has also been suggested ${ }^{23}$ despite evidence suggesting their limited reliability. ${ }^{102425}$ Such markers occurred frequently in subgroup IA but not in subgroup IB.

In addition, our preliminary findings with antibiotic therapy confirm the original suggestion by Suter and colleagues ${ }^{18}$ that food cobalamin malabsorption responds to antibiotics. However, this is only true for some patients. The presence of severe oxyntic gland gastric atrophy and achlorhydria may militate against improvement in absorption by antibiotic administration, regardless of microbial status. A role for $H$ pylori as a factor in at least some patients with food cobalamin malabsorption is supported by our data; however, its explanation is not clear and many infected subjects retain normal absorption. The mechanisms that produce food cobalamin malabsorption are clearly multiple. The mechanisms that are unrelated to achlorhydria will now require more attention and careful scrutiny.

This study was supported by grant DK 32640 from the National Institutes of Health and by the NIH National Center for Research Resources of the GCRC grant MO1 RR-43. Computational assistance was provided by the NIH NCRR GCRC MO1 RR-43 CDMAS project. We thank Dajun Qian for help with statistical analysis, Susie Nakao and the nurses of the Clinical Research Center at LAC-USC Medical Center for help in studying the subjects, Dr Tom Kawada and other members of the Division of Nuclear Medicine for help in preparing and the Division of Nuclear Medicine for help in preparing and administering the egg yolk test, Jeanne $M$ Howard for help with assistance, and Mo-Li Chen for technical assistance.

1 Carmel R. Malabsorption of food-cobalamin. In: Wickramasinghe SN, ed. Baillière's clinical haematology. Megaloblas2 Doscherholmen A, Swaim WR. Impaired assimilation of egg $\mathrm{Co}^{57}$ vitamin $\mathrm{B}_{12}$ in patients with hypochlorhydria and after $\mathrm{Co}^{57}$ vitamin $\mathrm{B}_{12}$ in patients with hypochlorhydria and
gastric resection. Gastroenterology 1973;64:913-19.

3 Streeter AM, Duraiappah B, Boyle R, et al. Malabsorption of vitamin B12 after vagotomy. Am $\mathcal{F}$ Surg 1974;128:340-3. 
4 del Corral A, Carmel R. Transfer of cobalamin from the cobalamin-binding protein of egg yolk to $\mathrm{R}$ binder of human

5 Carmel R. In vitro studies of gastric juice in patients with food-cobalamin malabsorption. Dig Dis Sci 1994;39:251622.

6 Saltzman JR, Kemp JA, Golner BB, et al. Effect of hypochlorhydria due to omeprazole treatment or atrophic gastritis on protein-bound vitamin $\mathrm{B}_{12}$ absorption. $\mathcal{f} \mathrm{Am}$ Coll Nutr 1994;13:584-91.

7 Carmel R. Cobalamin, the stomach and aging. Am 7 Clin Nutr 1997;66:350-9.

8 Carmel R, Green R, Jacobsen DW, et al. Serum cobalamin, homocysteine, and methylmalonic acid concentrations in a multiethnic elderly population: ethnic and sex differences in cobalamin and metabolite abnormalities. Am $\mathcal{F}$ Clin Nutr 1999;70:904-10.

9 Doscherholmen A, Silvis S, McMahon J. Dual isotope Schilling test for measuring absorption of food-bound and free ing test for measuring absorption of food-bound and free

10 Carmel $\mathrm{R}$, Sinow RM, Siegel ME, et al. Food cobalamin malabsorption occurs frequently in patients with unexplained low serum cobalamin levels. Arch Intern Med 1988; 148:1715-19.

11 Lewin KJ, Riddell RH, Weinstein WM. Stomach and proximal duodenum: inflammatory and miscellaneous disorders. In: Lewin KJ, Riddell RH, Weinstein WM, eds. Gastrointestinal pathology and its clinical implications. New York: Igaku-Shoin, 1992:506-69.

12 Genta RM, Robason GO, Graham DY. Simultaneous visualization of Helicobacter pylori and gastric morphology: a new stain. Hum Pathol 1994;25:221-6.

13 Laine L, Marin-Sorensen M, Weinstein WM. Nonsteroidal antiinflammatory drug-associated gastric ulcers do not require Helicobacter pylori for their development. Am $\mathcal{F}$ Gastroenterol 1992;87:1398-402.

14 Gottlieb C, Lau KS, Wasserman LR, et al. Rapid charcoal assay for intrinsic factor (IF), gastric juice unsaturated $B_{12}$ binding capacity, antibody to IF, and serum unsaturated $\mathrm{B}_{12}$-binding capacity. Blood 1965;25:875-84.

15 Skak-Nielsen T, Holst JJ, Nielsen OV. Role of gastrinreleasing peptide in the neural control of pepsinogen secretion from the pig stomach. Gastroenterology 1988;95:121620.

16 Steinberg WM, King CE, Toskes PP. Malabsorption of protein-bound cobalamin but not unbound cobalamin during cimetidine administration. Dig Dis Sci 1980;25:188 92.

17 Marcuard SP, Albernaz L, Khazanie PG. Omeprazole therapy causes malabsorption of cyanocobalamin (vitamin B12). Ann Intern Med 1994;120:211-15.

18 Suter PM, Golner BB, Goldin BR, et al. Reversal of proteinbound vitamin $B_{12}$ malabsorption with antibiotics in atrophic gastritis. Gastroenterology 1991;101:1039-45.

19 Carmel R, Perez-Perez GI, Blaser MJ. Helicobacter pylori infection and food-cobalamin malabsorption. Dig Dis Sci 1994;39:309-14.

20 Lindgren A, Bagge E, Cederblad A, et al. Schilling and protein-bound cobalamin absorption tests are poor instruments for diagnosing cobalamin malabsorption. F Intern Med 1997;241:477-84.

21 Carmel R, Aurangzeb I, Qian D. Characterization of food-cobalamin malabsorption: demographic, $H$ pylori and food-cobalamin malabsorption: demographic, H pylori and

22 Gutierrez O, Melo M, Segura AM, et al. Cure of Helicobacter pylori infection improves gastric acid secretion in patients with corpus gastritis. Scand f Gastroenterol 1997;32:664-8.

23 van Asselt DZB, de Groot LCPGM, van Staveren WA, et al. Role of cobalamin intake and atrophic gastritis in mild cobalamin deficiency in older Dutch subjects. Am 7 Clin Nutr 1998;68:328-34.

24 Dawson DW, Sawers AH, Sharma RK. Malabsorption of protein-bound vitamin $\mathrm{B}_{12}$. $B M \mathcal{H}$ 1984;288:675-8.

25 Miller A, Slingerland DW, Hall CA, et al. Food-bound $\mathrm{B}_{12}$ absorption and serum total homocysteine in patients with

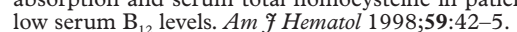

